\title{
Benefits of exploiting wind power at sea in Vietnam
}

\author{
Nguyen Tan Danh ${ }^{1 *}$ and Le Minh Quang ${ }^{2}$ \\ ${ }^{1}$ IT Faculty, FPT University, Ho Chi Minh City, 700000, Vietnam. \\ ${ }^{2}$ Language Faculty, Ho Chi Minh City Open University, Ho Chi Minh City, Vietnam, 700000, \\ Vietnam
}

\begin{abstract}
Climate change and greenhouse gas emissions from production activities are making it more difficult for Vietnam to approach the millennium goal. In order to ensure economic development in a sustainable environment, the development trend of green energy in the world which includes offshore wind power is considered a breakthrough solution. With a large proportion of greenhouse gas emissions, climate change is making it difficult for Vietnam to approach the millennium goal of ensuring economic development in a sustainable environment. The breakthrough solution now is the development trend of green energy, including offshore wind power. This article discusses the benefits that this energy source brings and suggests some effective solutions.
\end{abstract}

\section{Introduction}

According to the International Energy Organization, the global offshore wind power has the potential to reach $420,000 \mathrm{TWh}$ annually, 18 times more than the current demand of the world. As early as 1991, with the first offshore wind power project in Vindeby, Denmark built with $11450 \mathrm{~kW}$ turbines, a total capacity of $5 \mathrm{MW}$ at a depth of $4 \mathrm{~m}$ near shore and was dismantled in 2017 with more than 25 years life cycle. Recently, offshore wind power projects have grown much larger up to several gigawatts with larger turbines up to 12 megawatts and at great depths close to 200 meters and offshore more than 100 kilometers [1]. Before 2016, the investment cost per MWh of wind power was up to 200 USD. Recently, with legal and technological improvement, the price has dropped to about 100 USD / 1MWh. Especially, there is a bidding project in the UK in 2019 only about 50 USD / $1 \mathrm{MWh}$.

\subsection{The current status of using wind power in Vietnam and other countries}

Wind power uses the kinetic energy of the moving air in the earth's atmosphere to generate electricity. Unlike many other types of energy such as hydroelectricity, thermal power, etc. in the process of construction and operation with many environmental impacts, wind energy is considered a clean, renewable energy source [2]. During the operation of wind power

\footnotetext{
* Corresponding author: doraemonof2050@gmail.com
} 
plants, there are almost no $\mathrm{CO} 2$ emissions, but during the construction and operation of wind power, there are still some environmental impacts that should be considered. The wind at sea is a common trend of many countries around the world. In Vietnam in recent times, there have been many policies supporting the development of wind power exploitation at sea [3].

The offshore wind power market has been increasing steadily every year by $30 \%$ from 2010 to 2018. There are about 150 major marine wind farms in operation and strongly increasing in 2018 in the UK, Germany, Denmark, the US, and China. Currently, Europe has installed $20 \mathrm{GW}$ of offshore wind power and has a support policy that will quadruple by 2030 to $80 \mathrm{GW}$. The International Energy Organization forecasts that by 2040, the global offshore wind power will have investment and development capital of about 1 trillion USD with an annual growth rate of installed capacity of $13 \%$. Countries and territories that are also centers for offshore wind power development by 2040 are EU (Denmark, Germany, Netherlands, Ireland), UK, USA, China, Japan, India, Korea. , Taiwan (China). The installed capacity efficiency of offshore wind farms reaches $50 \%$, much higher than that of solar PV by nearly $20 \%$ and wind power on land $30 \%$.

According to the World Bank, in 2019, Vietnam has a potential of $475 \mathrm{GW}$ of offshore wind power in waters with a depth of less than $200 \mathrm{~m}$. Currently, Vietnam's total power plants of $40 \mathrm{GW}$ are operating with the main sources of hydropower, coal-fired thermal power and are basically running out [2]. Therefore, with the potential for offshore wind power many times higher than existing capacity, it is possible to meet current and future power demand.

Our country's coastal area, especially the southern region, has an area of about 142,000 $\mathrm{km} 2$, depth from $0 \mathrm{~m}-60 \mathrm{~m}$, with very good potential for marine wind power development [4]. According to the wind speed data, this area achieves average wind speed at the altitude of $100 \mathrm{~m}$, which is more than 7-10m / s. Currently, the first Bac Lieu sea wind farm with a capacity of $100 \mathrm{MW}$ has been operating providing about 300 million $\mathrm{kWh} /$ year and by 2025, it will reach 1,000 MW or 3 billion $\mathrm{kWh} /$ year.

Specifically, the wind turbine farms in Bac Lieu province have been operating well and bring high economic efficiency, the chance of capital recovery is about ten years, compared with the life of turbines of 50 years. The sea wind farm currently contributes to the local budget with a stable income, such as Bac Lieu province reaching 76 billion VND / year, when completed, the 1,000 MW wind farm will reach nearly 760 billion per year. In particular, the Thang Long super project off Binh Thuan province with a capacity of 3.4 GW is undergoing a feasibility study from 2019 and can be completed before 2030, will bring the position of an offshore wind power powerhouse for Vietnam [5].

\subsection{The environmental impacts of wind energy extraction}

\subsubsection{Impact on ecological environment}

Due to the requirement of wind resources, wind farms are often built on bare land with little shielding. However, wind farms have the least affected land area in electricity production types such as thermal power, hydropower, etc. The land area affected in wind power projects here is mainly related to auxiliary works systems such as lines, control stations, transformer stations, etc [6]. According to research from 2000 - 2009 by the National Renewable Energy Laboratory (National The Renewable Energy Laboratory of US) found that an average of only $1.1 \%$ of the total wind farm area is subject to surface disturbance, and only $0.43 \%$ of the land is permanently affected by the installation of wind power. A wind farm has an average area of about 63 hectares / MW, but only 0.27 hectares of area 
are permanently affected per MW of wind power. The remaining land in the wind power plant can be used for other purposes such as cultivation, farming, tourism, etc.

In addition, the construction phase of wind power plants is often faster than the construction phase of other energy projects. The reason is that the turbine equipment is usually manufactured in the factory and transported to the assembly site. Due to shortening the construction process, the impact on wind power plants' construction is not too large and long-term [4].

The biggest effects of wind turbine columns on wildlife are birds and bats. Bats can be injured by colliding with turbine columns and propellers. Especially when the propeller is working, it creates an air turbulence area around the blade, causing the bat's ultrasonic waves to abnormally bend, making it difficult for the bats to determine the direction to lead the collision [7]. A study in the United States in 2013, wind turbines killed more than 600,000 bats.

Like bats, flying birds are also victims of wind turbines. The motions of turbine blades are movements that have never existed in nature before, so birds often don't have enough evasive reflexes. Especially for migratory birds, which often fly with a stable trajectory to save energy, it is often difficult to evade if the wind turbines are on the bird migration path.

Wind power farms can affect weather in the vicinity. The turbine blades increase the vertical mixing of heat and steam, which in turn leads to variations in temperature, precipitation and wind direction. In general, wind farms result in mild warming at night and mild cooling during the day [3]. Depending on the specific conditions, this effect can have different consequences. For example, a slight increase in temperature at night can be helpful in farming practices by reducing frost damage and prolonging the growing season [8].

This turbulence from the spinning wind turbine blades increases the longitudinal blend of heat and steam that affects meteorological conditions in the wind direction, including precipitation [1]. According to research published in Science 9/2018, researchers indicate that wind and solar farms in the Sahara desert in Africa slow down global warming and increase amount of rain. Although the increase in rainfall is minimal, there are many benefits to Africa's hot and dry region.

As mentioned above, wind farms are usually located in large, open spaces. Wind turbines are usually located at the height of $50-100 \mathrm{~m}$ to obtain strong and stable wind sources easily. Therefore, the construction of wind farms will disrupt the natural landscape of the area. This can cause negative impacts if the area where the wind power plant is located has an important natural and cultural heritage. In 2011, UNESCO expressed concern about the impact of the planned wind farm near Mont Saint Michel Monastery. This is one of the most famous places in France with about 3 million visitors visiting each year. UNESCO recognizes mont Saint Michel Monastery and its bay as a World Heritage Site.

\section{Method}

The article compares the figures of the journals and Vietnam's data to analyze the points mentioned more clearly. In fact, in some areas of Vietnam, the wind farms have a role in adorning the landscape. Wind turbines are usually very tall and stand out against a landscape and give a modern feel [2]. Some parts of the world see wind farms as symbols of energy independence and local prosperity. In Vietnam, Cong Ly wind power plant in Bac Lieu province when completed construction has become an attractive tourist destination.

When operating wind turbines, there will be problems with noise and electromagnetic waves. The noise of the wind rotor during operation will affect human activities. This noise 
is caused by mechanical movements in the turbine, especially noise when the propeller moves through the air [7]. The noise especially increases with the high speed of the turbine. In addition, there is a risk of noise being transmitted from wind turbines to the foundation base to spread into the ground. Because a well-vibrating solid has little energy loss, the noise can be dispersed in this form very far (Figure 1).

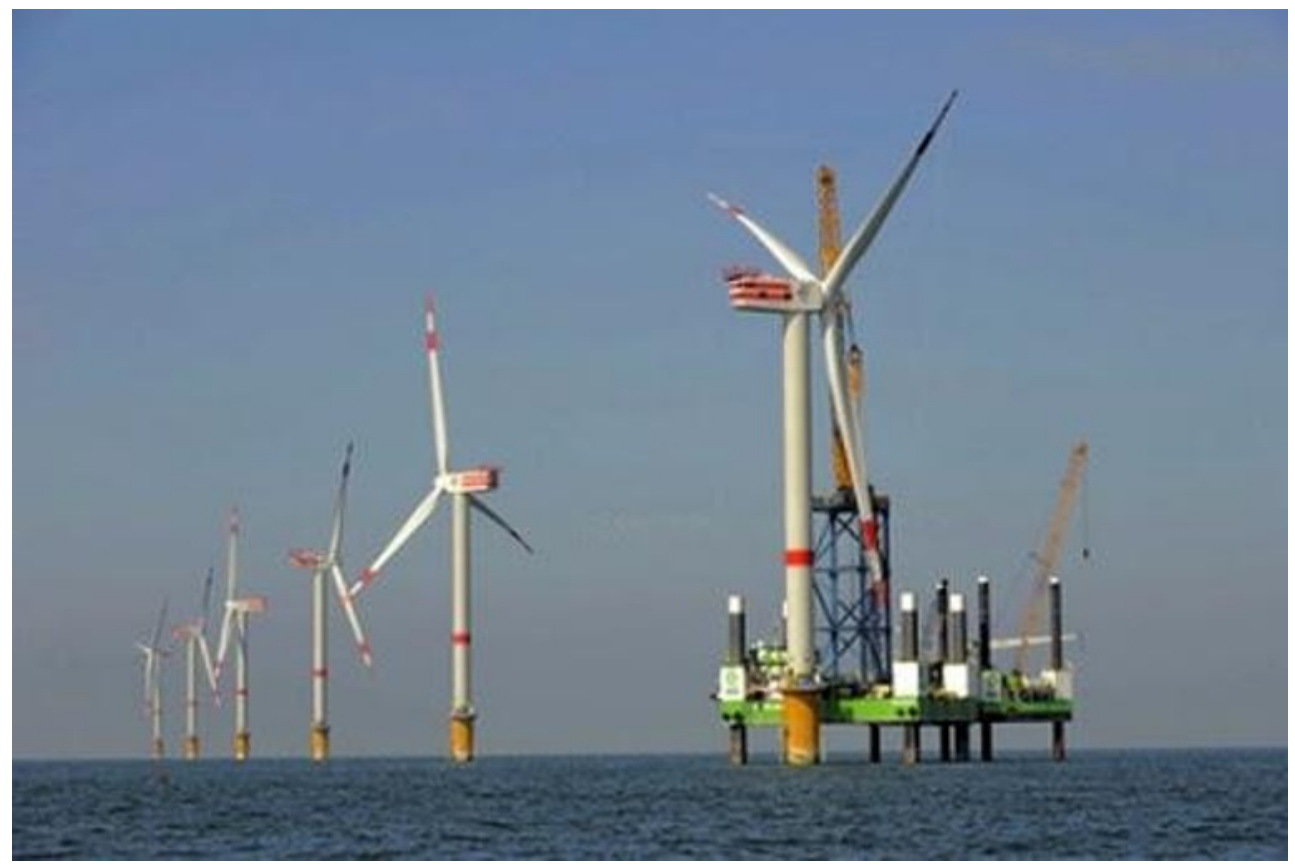

Fig 1. The first wind power plant in Vietnam

Under the provisions of Circular No. 39/2010 / TT-BTNMT on national technical regulations on the environment, the maximum noise limit for common areas is $70 \mathrm{dBA}$ equivalent to an engine's noise. Car while operating. Noise affects people in 3 aspects: Masking sounds that need to hear reduces the natural response of people to sound; causes diseases of the hearing and nervous system, indirectly causes a cardiovascular disease; Chronic high noise exposure leads to dementia and irreversible deafness. Even living in noise with high intensity, people can suffer psychosis due to fatigue, stress, tinnitus, vestibular disturbances, and neurological effects. Not only that, the noise also affects the communication - communication process, etc. That will have a strong impact on psychology as it is easy to arise feeling uncomfortable and irritable [8].

In addition, a controversial impact is the impact of infrasound waves has a lot in the wind on people. Sound waves are lower than the human hearing threshold, and their frequency is less than $20 \mathrm{~Hz}$. When the body is affected by intense infrasound waves, the same frequency as the body's internal organs' inherent frequency, a harmful resonance will immediately occur [3]. For example, infrasound with a frequency of $8 \mathrm{~Hz}$ coincides with the brain's pulsating frequency will cause a feeling of fear, depression, confusion, anger, etc. Many studies show that, infrasound waves affect extreme to human health. Sound waves are suspected to be the cause of marine accidents, when these vehicles enter the area where the infrasound waves are concentrated with high intensity, is the cause of the anomalous phenomena in this area.

During operation, wind turbines always generate electromagnetic waves coming from the operation of generators, transformers, etc. This can affect radar stations, communication 
networks, radio and television. This impact is greater when the wind columns are usually placed at the height of $50-100 \mathrm{~m}$.

Also, rotating wind turbines produce "flashes of light", which is because the blades partially obscure the sunlight when operating to create a flicker. This phenomenon will cause discomfort to human activities in the affected area. This can be avoided by shutting down the wind turbine during flickering solar hours or properly locating wind turbines away from residential areas.

\section{Results and discussion}

Types of renewable energy at sea include wave energy, wind, tides, currents, and solar energy. In Vietnam, the most feasible renewable energy at sea is wind energy and solar energy. For remote islands, implementing the goals set out in the Resolution to ensure electricity is available. Renewable energy is the key solution for a stable, affordable energy supply. Accordingly, the purchase price for wind power projects at sea is $2,223 \mathrm{VND} / \mathrm{kWh}$ (equivalent to 9.8 UScent $/ \mathrm{kWh}$ ). The above price does not include value-added tax, and electricity purchase price is adjusted according to fluctuations of the exchange rate VND / USD.

In the context that our country's hydropower resources are not much, coal energy is also facing many difficulties in fuel sources, affecting the environment, etc. nuclear power cannot be deployed in the near future, wind energy in Vietnam [8]. South is opening a new trend for the country's energy sources. With the new resolution on sustainable development of marine economy and regulations on wind power selling price increase will stimulate investors to build more wind power projects. Recently, the Bac Lieu wind power project at sea with a 99.2 MW capacity with a total investment of over VND 5,200 billion completed phase 1 in January 2016. Currently, the investor is preparing to implement the third phase of the project, building 71 more wind turbine pillars, turning the alluvial land of Bac Lieu into the largest "wind power field" in the West. In addition, a wind power project at sea is also interested in the offshore wind power project of Ke Ga cape, Binh Thuan province, with an expected installation capacity of about 2,400MW (equivalent to Son La hydroelectricity capacity). Currently, this project is carrying out marine research and survey. If successful, the project will create a turning point for the exploitation of wind energy at sea in Vietnam as well as in the world [6].

As analyzed above, the offshore wind energy resource is the most powerful new energy source and investment in the world today. Wind energy at sea is converted to electricity by wind turbines and built with a longer lifespan to suit the harsh conditions at sea. On the other hand, it will be the tourist attractions, study tours, and "eye of god" to help strengthen national sovereignty security at sea.

For wind power plants, construction on land is always the first thought of investors. Compared to construction at sea, wind power plants on the mainland have several advantages such as simple technology and structure, easy construction, so the capital requirement is not too high, the operation and supervision are convenient. However, with the wind power plants on the mainland, there are a number of obstacles and limitations, including:

Although wind power farms have the lowest land use coefficient among different power generation types, they require large, airy space and high working height to catch more wind. Due to the above requirements, along with socio-economic development, clean spaces convenient for land-based renewable energy projects are increasingly scarce, and if any, small areas cannot meet the scale [9].

In land areas with suitable areas for large wind power plants, they are often far from residential areas and far from places with large electricity consumption such as industrial 
parks and big cities. Therefore, the transmission problem is difficult, the loss rate on the transmission line is large [5]. The impacts on people's livelihood and socio-economic development activities on the mainland should also be taken into account when building wind power plants.

For these reasons, building wind power plants at sea is a common trend of countries around the world, the construction of wind power plants at sea has many advantages as follows. The wind source is stable, the space is not blocked like on the mainland. The coastal area is home to a high population concentration and is also a place that consumes a lot of energy. According to statistics, about $50.03 \%$ of Vietnam's population is concentrated in the coastal area while the land area of this area only accounts for $41 \%$ of the country's area. Therefore, if the wind farm is located offshore, electricity transmission to a place where electricity consumption is very convenient minimizes waste on the line.

In addition, the wind turbine supports on the sea will reduce the impact of wind waves on the coast, thereby reducing coastal erosion and erosion. Marine turbine pillars also provide shelter for marine organisms, thereby attracting larger creatures to forage, creating diverse marine ecosystems.

\section{Conclusion}

To accomplish this, the State needs to have national policies on offshore wind power, that means they soon formulate a national strategy for offshore wind power development, then have a marine spatial plan for the development of offshore wind power in Vietnam in association with the National Strategy on marine wind energy development to 2030, with a vision to 2045. At the same time, it is necessary to build, supplement and complete the national institutional and policy framework on licensing, appraisal, environmental impact assessment, marine lease, and development of offshore wind power projects and other marine energies. Along with that, building and updating the electricity purchase price policy system, connecting the national grid, the policy of renting the sea surface, and the national carbon tax policy. On the other hand, the State should have a scientific research program on offshore wind power, human resource training and technology transfer.

\section{Acknowledgements}

The author (Nguyen Tan Danh) would like to show thanks to FPT University where he is working. The co-author (Le Minh Quang) also likes to show thanks to Ho Chi Minh city Open Univeristy where he is taking an English course, for financial support.

\section{References}

1. De Giorgi, M. G., Ficarella, A., \& Tarantino, M, Assessment of the benefits of numerical weather predictions in wind power forecasting based on statistical methods. Energy. 367 (2011)

2. Holttinen, H., Meibom, P., Orths, A., Lange, B., O'Malley, M., Tande, J. O., ... \& Smith, J. C, Impacts of large amounts of wind power on design and operation of power systems, results of IEA collaboration. Wind Energy. 142 (2011)

3. Tsikalakis, A. G., Katsigiannis, Y. A., Georgilakis, P. S., \& Hatziargyriou, N. D, Determining and exploiting the distribution function of wind power forecasting error for the economic operation of autonomous power systems. In 2006 IEEE Power Engineering Society General Meeting. IEEE. (2006). 
4. Margaris, I. D., Papathanassiou, S. A., Hatziargyriou, N. D., Hansen, A. D., \& Sorensen, P, Frequency control in autonomous power systems with high wind power penetration. IEEE Transactions on sustainable energy. 32 (2012)

5. Sant, T., Buhagiar, D., \& Farrugia, R. N, Exploiting the thermal potential of deep seawater for compensating losses in offshore hydraulic wind power transmission pipelines. IET Renewable Power Generation. 1010 2016).

6. Nguyen, K. Q, Wind energy in Vietnam: Resource assessment, development status and future implications. Energy Policy. 352 (2007).

7. Hoi, H. T., \& Danh, N. T, Greening Houses in the Age of Climate Change. In IOP Conference Series: Earth and Environmental Science. IOP Publishing, 5051 (2020)

8. Luu, C., Von Meding, J., \& Kanjanabootra, S, Balancing costs and benefits in Vietnam's hydropower industry: A strategic proposal. International Journal of Disaster Resilience in the Built Environment. (2017).

9. Vo, H. T., Le, V. T., \& Cao, T. T. H, Offshore wind power in Vietnam: Lessons learnt from Phu Quy and Bac Lieu wind farms. In Vietnam Symposium on Advances in Offshore Engineering. Springer, Singapore. (2018)

10. Curto, D., Van Doan, B., Franzitta, V., Montana, F., Nguyen, N. Q., \& Sanseverino, E. R, Wave and Wind Energy Systems Integration in Vietnam: Analysis of Energy Potential and Economic Feasibility. In 2020 IEEE International Conference on Environment and Electrical Engineering and 2020 IEEE Industrial and Commercial Power Systems Europe (EEEIC/I\&CPS Europe) IEEE. (2020). 